\title{
Asymmetrical lipomatosis: report of two cases
}

\author{
G. Enzi ${ }^{1}$, M. Digito ${ }^{1}$, G. Baldo Enzi ${ }^{1}$, B. Perin ${ }^{2}$ and D. Fiore ${ }^{2}$ \\ Departments of ${ }^{1}$ Internal Medicine and ${ }^{2}$ Radiology, University of Padua, Italy
}

\begin{abstract}
Summary: We report on two patients with an asymmetrical expansion of fat tissue. At computed tomography, lipomatous tissue proved to be superficially located in one patient and both subcutaneously and deeply located in the second. Signs and symptoms of a peripheral neuropathy were observed in both patients, who were otherwise asymptomatic. The lipolytic activity in post-heparin plasma was normal in both patients. The fat cell size of lipomatous tissue, obtained in one patient by percutaneous needle biopsy, was higher than that of contralateral, uninvolved adipose tissue. The adipose tissue lipoprotein lipase activity in lipomatous tissue was higher than that in normal tissue. High density lipoprotein (HDL), HDL and $\mathrm{HDL}_{3}$ cholesterol values were elevated in both patients but not exceeding 1 standard deviation the values of age and sex matched controls. Isoprenaline-stimulated lipid mobilization was similar in lipomatous and in control tissue.
\end{abstract}

\section{Introduction}

In most instances variation of body fat stores closely reflect variations in energy balance. In some diseases primarily affecting adipose tissue, such as capsulated lipomas and in lipomatosis, the formation and growth of fat masses seems to be independent of calorie balance. An abnormality in the mechanisms regulating triglyceride synthesis and mobilization in lipomatous cells can be suspected. Lipomatoses may therefore represent useful naturally occurring models of inborn errors in triglyceride metabolism in adipose tissue. In addition, the deep accumulation of lipomatous tissue can in some instances be responsible for space occupying syndromes of primary importance in clinical practice.

The diagnostic aid of computed tomography has given rise to rapid improvement in the identification and definition of superficial and deep lipomatosis in recent years. In the present paper we report on clinical, metabolic and tomographic aspects in a previously unreported type of lipomatosis.

\section{Case reports}

\section{Case 1}

In this patient, a 42 year old woman, lipomatosis developed at 13 years of age as a single lipomatous

Correspondence: G. Enzi M.D., Department of Internal Medicine, Policlinico, 35100 Padova, Italy

Accepted: 1 April 1985 mass in the abdominal wall and progressively spread to the right side of the thoracic wall, neck, face and skull. Over the next few years the right arm became progressively involved up to the dorsal side of the hand. At 40 years of age the left thigh became hypertrophic. The fatty tumours were firm and tense, due to the deep location and the tension of the aponeurotic fasciae. The uninvolved subcutaneous adipose tissue was frankly atrophic. Muscular weakness, loss of cutaneous sensitivity and hypoaesthesia at the lower limbs, more pronounced in the left foot, manifested at 30 years of age. Routine biochemical examination, including haematology, liver and renal function tests, hormonal and metabolic parameters were consistently normal. Alcohol consumption was denied.

\section{Case 2}

In this patient, a 26 year old woman, a progressive increment of the girth of the left leg was noted from 20 years of age. A few years later a soft, undelimited mass grew asymmetrically at the left side of the abdominal wall. Concomitantly a progressive atrophy of the subcutaneous fat of the upper body occurred. In 1982 the patient underwent plastic surgery for abdominal and crural lipectomy. In 1983 muscular weakness and hypoaesthesia at the lower limbs appeared. Routine biochemical investigations were consistently normal. Alcohol consumption was denied.

(C) The Fellowship of Postgraduate Medicine, 1985 


\section{Materials and methods}

Metabolic studies included the determination of postheparin lipase activity in plasma (PHLA), carried out in both patients, lipoprotein lipase activity in adipose tissue (AT-LPL) and adrenergic stimulated lipolysis, carried out in only one patient (Case 2). PHLA was determined according to Ehnholm et al. (1974) in blood samples taken $10 \mathrm{~min}$ after the injection of $60 \mathrm{U} /$ $\mathrm{kg}$ body weight of sodium heparin. AT-LPL was measured in eluates of adipose tissue samples obtained by percutaneous needle biopsy performed symmetrically at the anterior crural areas of both legs, according to Pykälisto et al. (1975). Adrenergicstimulated lipolysis was measured using isoprenaline, $10^{-5} \mathrm{~mol}$, according to a previously described method (Enzi et al., 1983). Fat cell size was measured on adipose tissue microsamples (Enzi et al., 1982). ATLPL and the lipolytic response was then calculated per gram of adipose tissue and per $10^{5}$ cells. Plasma high density lipoprotein (HDL) fractions were obtained by selective polyanion precipitation according to Gidez $e t$ al. (1979) and their cholesterol content was determined enzymatically (Baldo-Enzi et al., 1984).

Both patients underwent electromyographic studies including motor conduction velocity, sensory conduction velocity and distal latencies.

Fat distribution abnormalities were investigated by computed tomography (CT).

\section{Results}

\section{Clinical findings}

In both patients there was tendon areflexia, a loss of vibratory sensation and muscular weakness. Hyperhydrosis at the ankle and abnormal cutaneous vascularization (cutis marmorata) without peripheral artery disease were observed in Case 1. The motor conduction velocity at the peroneal nerve was reduced in both patients (Case 1: $42.0 \mathrm{~m} / \mathrm{s}$; Case 2: $44.6 \mathrm{~m} / \mathrm{s}$; controls: $50.3 \pm 0.8 \mathrm{~m} / \mathrm{s})$. Sensory conduction velocity at the sural nerve was also reduced in the patients (Case 1: $42.2 \mathrm{~m} / \mathrm{s}$; Case 2: $44.6 \mathrm{~m} / \mathrm{s}$; controls: $48.4 \pm 1.2 \mathrm{~m} / \mathrm{s})$. Motor and sensory conduction velocities at the ulnar nerve and distal latencies were within the limits of normality in both patients.

\section{Radiological findings}

Computed tomography showed the asymmetrical distribution of lipomatous tissue. Differences emerged in fat location in the two patients: in Case 1 the lipomatous tissue had massively infiltrated the muscle bands involving almost exclusively the subfascial adipose tissue; pericardial, mediastinal and peri- hepatic lipomatosis was also demonstrated. Several round shaped liquid filled cysts occupied the hepatic $\varrho$ parenchyma (see Figures 1-3). In Case 2 lipomatous $\stackrel{\hookrightarrow}{.}$ tissue was mainly located in the subcutaneous fat layer, with minor displacement of the subfascial structures and without muscular infiltration.

\section{Metabolic findings}

Whole serum cholesterol, phospholipids and triglycerides were normal in both patients. Plasma $\overrightarrow{0}$ $\mathrm{HDL}, \mathrm{HDL}_{2}$ and $\mathrm{HDL}_{3}$ cholesterol values were $\overrightarrow{-}$ slightly elevated, but did not exceed by 2 s.d. the mean $\vec{\omega}$ values of age and sex matched controls. Plasma PHLA was similar in patients and controls. AT-LPL was 3 higher in lipomatous tissue than in control tissue both when expressed in terms of wet weight and on per cell -

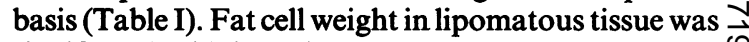
significantly higher than in control tissue (mean- 9 \pm s.d.: $1.10 \pm 0.02$ v. $0.91 \pm 0.3 \mu \mathrm{g} ; P<0.001)$.

Adrenergic-stimulated lipolysis was similar in 0 lipomatous and in control tissue both when expressed in terms of tissue weight and on per cell basis (Table I). $\vec{\rho}$

\section{Discussion}

The term lipomatosis refers to a number of diseases $\overrightarrow{0}$ characterized by a progressive growth of unencari o sulated fat masses. Lipomatous tissue can form and grow inside the subcutaneous fat layer as well as in deeply located sites, leading to organ dislocations or space occupying syndromes. Up to now, a number of clinically different lipomatoses have been categorized, $\frac{\varnothing}{\varnothing}$ with defined signs and symptoms and a predictable $\varrho$

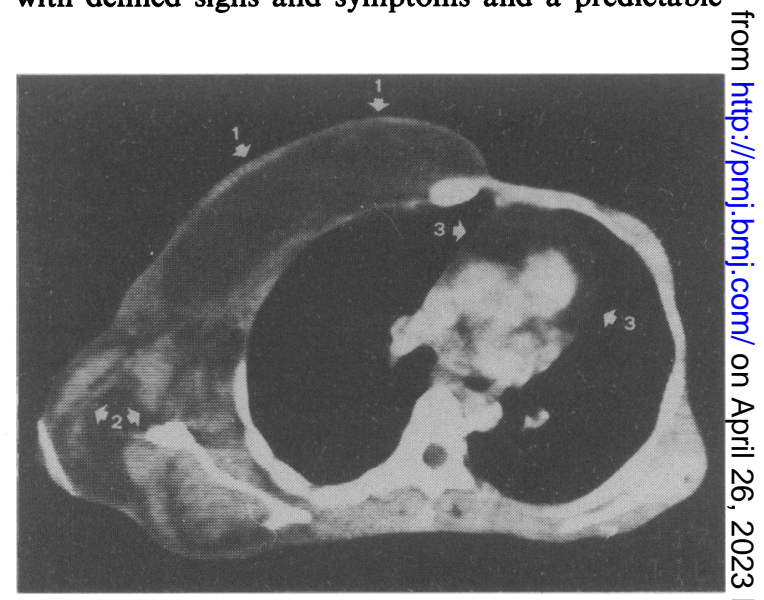

Figure 1 Computed tomography scan at thoracic level (Case 1): lipomatous tissue asymmetrically occupies the chest wall (arrow 1) and infiltrates the scapular muscles (arrow 2). A pericardial accumulation of fat tissue is present (arrow 3). 


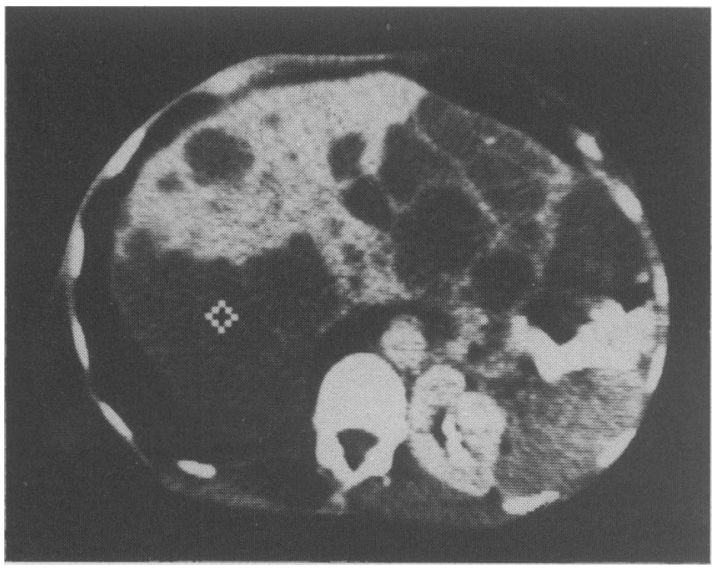

Figure 2 CT scan at abdominal level (Case 1): several round-shaped cysts occupy the liver parenchima. Abdominal lipomatosis can be excluded.

course, such as multiple symmetric lipomatosis (Enzi, 1984), pelvic lipomatosis (Engels, 1959), renal sinus lipomatosis (Windholz, 1957; Poilly et al., 1969), mediastino-abdominal lipomatosis (Enzi et al., 1984), lipomatosis dolorosa (Dercum, 1942).

An asymmetrical formation and growth of lipomatous tissue characterizes the type of lipomatosis here described. In these two patients lipomatosis manifested after puberty with a slow progressive trend to spread. Concomitantly adipose tissue in uninvolved areas underwent atrophy. A further feature of asymmetrical lipomatosis is the occurrence of signs and symptoms of a peripheral neuropathy at the lower limbs. Sensory, motor and autonomic neuropathies have been reported in association with other lipomatoses (Fessel, 1971; Rosenberg et al., 1963), namely, multiple symmetric lipomatosis (Greene et al., 1970; Enzi et al., 1984) and adiposis dolorosa. Neural disturbances have been demonstrated to be related to nerve compression by fat masses only occasionally. A common metabolic abnormality in adipose tissue and in nervous tissue could be postulated to explain the coexistence of lipomatosis and neuropathies.

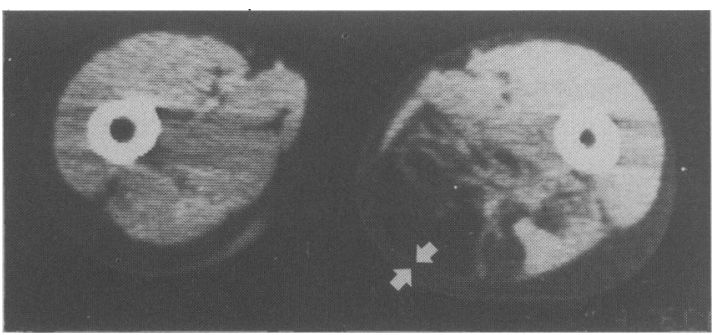

Figure 3 Asymmetrical lipomatosis of the thigh (Case 1): lipomatous tissue infiltrates the muscular bands, developing below the aponeurotic fasciae (arrows) of the muscles.

At present no explanations are available for the zonal involvement of adipose tissue. At conventional light microscopy lipomatous tissue did not differ from normal adipose tissue. In other forms of lipomatosis electron microscopy was able to demonstrate abnormalities consistent with a neoplastic-like proliferation (Cinti et al., 1983). Fat cell size in lipomatous tissue in the patient studied was significantly larger than in normal tissue; the fatty tumour formation could hence be explained by a hypertrophic mechanism.

In both patients the post-heparin lipolytic activity in

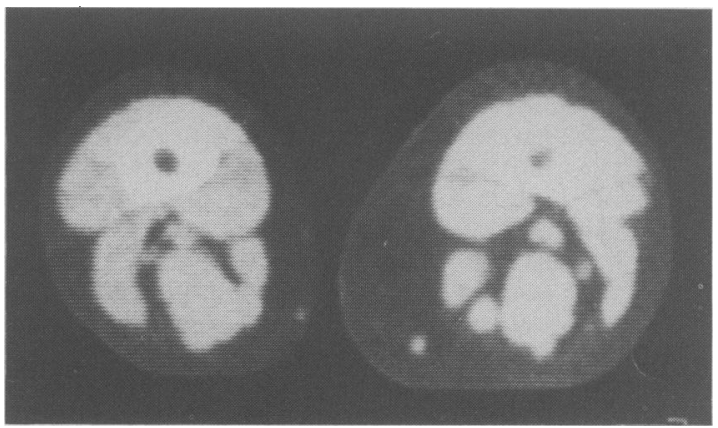

Figure 4 Asymmetrical lipomatosis of the thigh (Case 2): the expansion of lipomatous tissue mainly involves the subcutaneous fat layer. A slight muscle displacement without infiltration is present.

Table I Adipose tissue lipoprotein lipase activity (AT-LPL) and adrenergic stimulated lipolysis in lipomatous and in normal tissue of a patient (Case 2) with asymmetrical lipomatosis, and in control tissues taken from the gluteal region of 12 normal females of 20-39 years of age

\begin{tabular}{lcccc} 
& \multicolumn{2}{c}{$A T-L P L$} & \multicolumn{2}{c}{ Lipolysis } \\
& $\mu \mathrm{M} / \mathrm{g} / \mathrm{min}$ & $\mu \mathrm{M} / 10^{5} \mathrm{cell} / \mathrm{min}$ & $\mu \mathrm{M} / \mathrm{mg} / 180 \mathrm{~min}$ & $\mu \mathrm{M} / 10^{5} \mathrm{cell} / 180 \mathrm{~min}$ \\
Lipomatous tissue & 122.4 & 13.4 & 48.4 & 533 \\
Normal tissue & 87.7 & 7.9 & 55.1 & 502 \\
Control tissues (range) & $12.9-73.7$ & $1.2-7.4$ & $19.0-67.5$ & $207-705$
\end{tabular}


plasma was normal. In the patient studied, the lipoprotein-lipase (LPL) activity in lipomatous tissue was higher than in control tissue. In other forms of lipomatosis an increased LPL production by lipomatous tissue has been demonstrated (Giudicelli $e t$ al., 1976; Enzi et al., 1983). Thus an increased triglyceride deposition in fat cells, related to the elevated AT-LPL activity could explain the hypertrophy of lipomatous cells and hence the formation of lipomatous masses.

\section{References}

BALDO-ENZI, G., BARONI, L., PICCOLI, A., BAIOCCHI, M.R. \& FELLIN, R. (1984). Cholesterol determination in HDL, $\mathrm{HDL}_{2}$ and $\mathrm{HDL}_{3}$ fractions after polyanion precipitation: a comparison between clinical extractive and totally enzymatic procedures. Clinica Chimica Acta, in press.

CINTI, R., ENZI, G., CIGOLINI, M. \& BOSELLO, O. (1983). Ultrastructural features of cultured mature adipocyte precursors from adipose tissue in multiple symmetric lipomatosis. Ultrastructural Pathology, 5, 145.

DERCUM, F. (1942). Adiposis dolorosa. American Journal of Medical Sciences, 104, 521.

EHNHOLM, C., GRETEN, H. \& BROWN, W.V. (1974). A comparative study of postheparin lipolytic activity and a purified human plasma triacylglycerol lipase. Biochimica et Biophysica Acta, 360, 68.

ENGELS, E.P. (1959). Sigmoid colon and urinary bladder in high fixation: roentgen changes stimulating pelvic tumour. Radiology, 72, 419.

ENZI, G. (1984). Multiple symmetric lipomatosis: an updated clinical report. Medicine, 63, 56.

ENZI, G., INELMEN, E.M., RUBALTELLI, F.F., ZANARDO, V. \& FAVARETTO, L. (1982). Postnatal development of adipose tissue in normal children on strictly controlled calorie intake. Metabolism, 31, 1029.

ENZI, G., DIGITO, M., MARIN, R., CARRARO, R., BARITUSSIO, A. \& MANZATO, E. (1984). Mediastino-abdominal lipomatosis: deep accumulation of fat mimicking a respiratory disease and ascites. Clinical aspects and metabolic studies in vitro. Quarterly Journal of Medicine, 53, 453.

ENZI, G., FAVARETTO, L., MARTINI, S., FELLIN, R., BARITUSSIO, A., BAGGIO, G. \& CREPALDI, G. (1983). Metabolic abnormalities in multiple symmetric lipomatosis: elevated lipoprotein lipase activity in adipose tissue with hyperalphalipoproteinemia. Journal of Lipid Research, 24, 566.
The AT-LPL-related increase in plasma HDL parti $\frac{2}{3}$ cles observed in multiple symmetric lipomatosis (Enzi⿱ et al., 1983) was not observed in asymmetricak lipomatosis.

A defect in adrenergic stimulated lipolysis, first? described in a child with severe emaciation and symmetrical adiposity at the extremities (Galton et al.믐 1974) and in adipose tissue of patients with multiples symmetrical lipomatosis (Enzi et al., 1977), can be@ excluded in asymmetrical lipomatosis.

ENZI, G., INELMEN, E.M., BARITUSSIO, A., DORIGO, P므 PROSDOCIMI, M. \& MAZZOLENI, F. (1977). Multiple symmetric lipomatosis. A defect in adrenergic stimulateচb lipolysis. Journal of Clinical Investigation, 60, 1221.

FESSEL, W.J. (1971). Fat disorders and periphera $1-$ neuropathy. Brain, 94, 531.

GALTON, D.J., GILBERT, J.P., RECKLESS, J.P.D. \& KAYE, J (1974). Triglyceride storage disease. A group of inborn errors of triglyceride metabolism. Quarterly Journal of Medicine, 43, 63.

GIDEZ, L.I., MILLER, G.J., BURNSTEIN, M. \& EDER, H.A (1979). Analysis of plasma high density lipoprotein sub classes by a precipitation procedure: correlation with preparative and analytical ultracentrifugation. In Reporb of the High Density Lipoprotein Methodology, K. Lippois, (ed). Workshop U.S. Department of Health, Education and Welfare. NIH Publication, No. 79-1661, p. 328. GIUDICELLI, Y.R., PECQUERY, B., AGL, C., JAMIN, C을ㄹ QUEVANVILLIERS, J. (1976). Lipoprotein lipase and hormone sensitive lipase activities in human subcutaneous lipomas: comparison with normal subcutaneous adipose tissue. Clinical Science and Molecular Medicine, 50, 315. ֶّ

GREENE, M.L., GLUECK, C.J., FUJIMOTO, W.Y. \& SEEG $\Omega$ ? MILLER, J.F. (1970). Benign symmetrical lipomatosis with gout and hyperlipoproteinemia. American Journal os, Medicine, 48, 239.

POILLY, J.N., DICKIE, J. \& JAMES, W.B. (1969). Renal sinus lipomatosis: a report of 26 cases. British Journal of? Urology, 141, 257.

PYKÄLISTO, O.J., SMITH, P.H. \& BRUNZELL, J.D. (1975) Determinants of human adipose tissue lipoprotein lipase. Journal of Clinical Investigation, 56, 1108.

ROSENBERG, B., HURWITZ, A. \& HERMANN, H. (1963). Dercum's disease with unusual retroperitoneal and 3 paravescical fatty infiltration. Surgery, 54, 451.

WINDHOLZ, F. (1957): The roentgen appearance of the central fat tissue of the kidney: its significance in urogra- $\frac{D}{2}$ phy. Radiology, 56, 202. 